Article

\title{
Assessing the Impacts of Population Growth and Climate Change on Performance of Water Use Systems and Water Allocation in Kano River Basin, Nigeria
}

\author{
Muhammad Tajuri Ahmad 1,2,*(D) and Naim Haie 1,3 \\ 1 CTAC, University of Minho, Azurem Campus, 4800-058 Guimarães, Portugal; naim@civil.uminho.pt \\ 2 Civil Engineering Department, Kano University of Science \& Technology, 713281 Wudil, Nigeria \\ 3 International Water Resources Association, 92027 Paris, France \\ * Correspondence: amtajuri@gmail.com; Tel.: +234-8032-171-047 or +351-253-510-200
}

Received: 16 October 2018; Accepted: 27 November 2018; Published: 1 December 2018

\begin{abstract}
Improving the performance of water use systems (WUSs) is essential for addressing the pressure on water resources for sustainability. Despite the potential impacts of population growth and global warming especially in semi-arid regions, the knowledge and understanding of WUSs and impacts of those main drivers of change on their performance are not available in the Kano River basin (KRB). This paper assesses these impacts on the performance of KRB, using the new and innovative Sefficiency (sustainable efficiency) framework, which incorporates quantity, quality, and beneficial aspects of water use in a comprehensive and systemic manner. We found that performance of the WUSs is sensitive to population growth and global warming under the scenarios considered. Kano River is relatively less sensitive to global warming impacts, while high population growth is dominant. Moreover, their combined effect will result in a reduction of downstream water by $70 \%$ and potential demands will far exceed the available supply by 2050. It is recommended that efficient management of water regarding the qualitative as well as quantitative aspects is very critical in KRB. This study can be regarded as the first step, and future studies may adopt the described methodology and can benefit from smart technologies, e.g., sensors and remote sensing.
\end{abstract}

Keywords: population growth; climate change; water allocation; Sefficiency; Kano River basin; water resources management

\section{Introduction}

Water management along river basins in semi-arid regions is a complex issue because there is a limited supply of water to satisfy the demand of all the sectors and environmental needs. Management of water resources has become more intricate, and drivers of change such as population growth and climate change are intensifying [1,2]. For instance, excessive population growth coupled with demographic change [3], and climate change impacts [4,5] are part of the significant trends coming up in Nigeria. Probably more importantly, these are projected to continue in future, thus increasing the pressure on water resources [6]. Changes in water availability can have serious repercussions on the sustainability of semi-arid environments [7], such as deteriorating the performance of storage reservoirs [8]. However, it is possible to make the most of the benefit of the available water resources by ensuring that all water is used efficiently. Therefore, the efficient use of water becomes more urgent.

The Kano River basin (KRB) of Northern Nigeria (Figure 1), a semi-arid region, has irrigation and urban water supply using a significant part of the available water resources. The use of water by these sectors is already causing water shortage that significantly affects the livelihoods of downstream 
users [9], and therefore has an essential role in the efficient use of water resources in the basin [10]. Thus, concerns about water scarcity in KRB should pay more attention to these sectors. The main challenges related to water resources in the basin are degradation in water quality, poor multi-sectoral coordination, water allocation problems, poor stakeholders' participation and growing competition for water among upstream and downstream areas and different sectors [10]. The unilateral decision by the Kano state government to construct a hydropower station at Tiga dam is an example of uncoordinated surface water uses which raises concern for water availability for KRIP (Kano River Irrigation Project), a major irrigation area in the Kano River basin. Generally, in this river basin, the knowledge and understanding of water use systems and impacts of main drivers of change on their performance across the basin are not available.

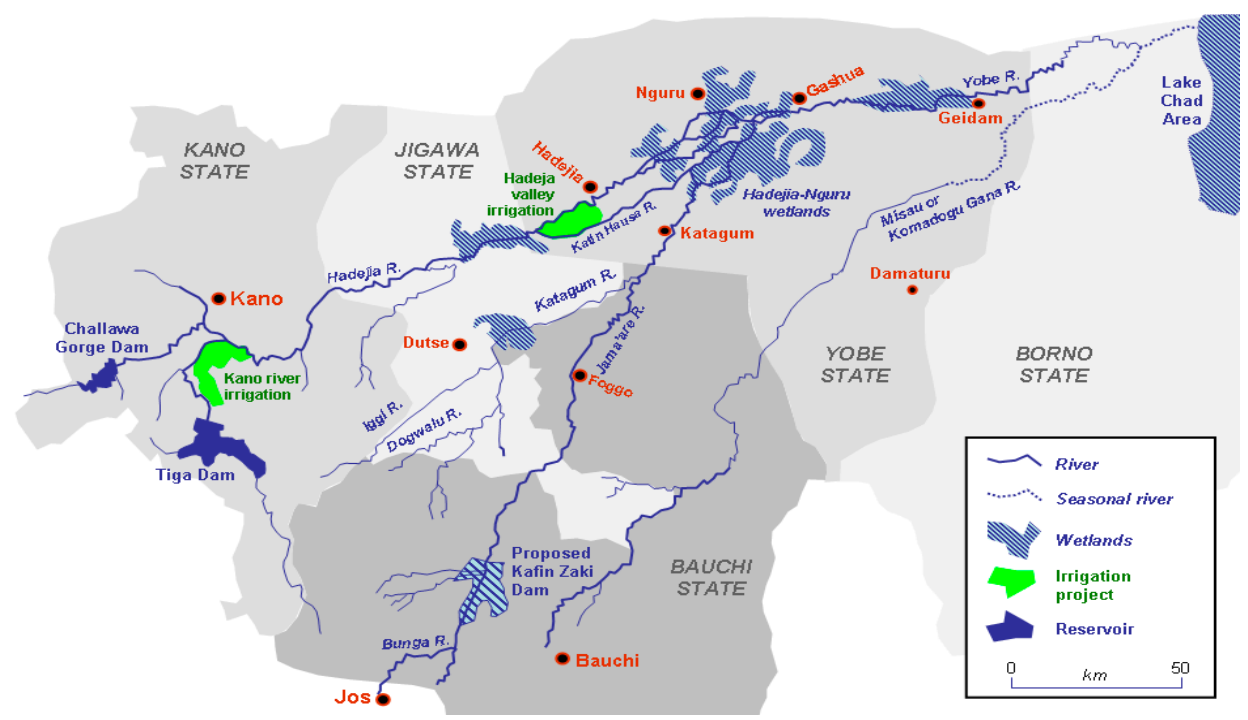

Figure 1. Tiga dam and Kano River (on the left) eventually flowing to Lake Chad.

Improving the performance of urban and irrigation schemes through various interventions is considered a vital issue for addressing the pressure on water resources [11-25]. However, efficiency is considered as one of the most important performance indicators for water resources systems management [26]. It was reported in de Fraiture \& Wichelns [27] that adequate land and water resources are available to satisfy global food demands in the next 50 years, but only if water is managed more efficiently. This depicts that increasing water use system's (WUS) performance in terms of efficiency remains one of the possible options for realizing the Sustainable Development Goals (UN-SDGs). For example, agricultural water consumption is expected to increase by about $20 \%$ globally by 2050 without improved efficiency measures [28] and water-use efficiency improvements are considered instrumental in addressing the projected $40 \%$ gap between demand and supply and mitigating water scarcities by 2030 [29]. Burt et al. [30] reported that monitoring the performance of water use, among others, is a basic requirement for water resources development and management evaluations and decision making. From these, we may infer that knowledge of performance of WUS becomes essential as water management needs become complex. Hence, evaluating a water use system to improve its performance for optimal productivity in the context of increasing demand for food and limited freshwater resources becomes crucial or a part of standardized procedures [30,31]. Moreover, better efficiency for WUS is recommended as one of the most important responses to climate change, unsustainable development and water shortage [32-36].

The potential impacts of population growth and global warming especially in water scarce areas, such as semi-arid, will continue to be a key concern for the future sustainability. This paper assesses the impact of population growth and climate change on performance of KRB. The analysis is based on evaluating the performance of KRB and KRIP using Sefficiency (Sustainable efficiency). 
The paper also provides detailed water balance for which required data was available. The analysis will help in providing facts and figures of the water availability and demand under future conditions and a spectrum of its variability and changes, which in turn can provide a sound basis for water (re)allocating policies.

\section{Materials and Methods}

\subsection{Description of the Study Area}

KRB is located in northern part of Nigeria (Figure 1). It is a sub-catchment of Hadejia River which eventually terminates in Lake Chad, an important transboundary basin in West Africa shared with Chad, Cameroon, Niger, and Nigeria. It is being drained by Rivers Kano and Challawa, and their tributaries-Watari, Yarkuto, Tatsawarki, and Salanta [37]. A brief description of the study area and key issues are presented below.

The climate is semi-arid. The mean annual precipitation is about $898 \mathrm{~mm}$ (maximum and minimum values are $1872 \mathrm{~mm}$ and $419.6 \mathrm{~mm}$ respectively). Temporal trends show that most of the total precipitation falls within five months (May-September) with August having the highest amount, whereas November-March form the dry periods [38]. The mean annual temperature ranges from $26{ }^{\circ} \mathrm{C}$ to $32{ }^{\circ} \mathrm{C}$ and relative humidity of $17-90 \%$. Temperatures are highest in late dry season in April and May with mean daily minimum temperatures of $24{ }^{\circ} \mathrm{C}$ and an average daily maximum of $38^{\circ} \mathrm{C}$. The coldest month is January with mean daily minimum temperatures of $13{ }^{\circ} \mathrm{C}$ and an average daily maximum of $30{ }^{\circ} \mathrm{C}$. Evaporation is in the range of $3500 \mathrm{~mm}$ to $4500 \mathrm{~mm}$ per year and its demand is generally higher than precipitation.

KRB supports an estimated population of over 3 million people, most of whom rely directly on this water for their domestic supplies and livelihoods through irrigated farming, fishing, and livestock herding and industrial activities. Kano River is regulated by Tiga dam (the largest dam in the basin), having a designed storage capacity of about $1429 \mathrm{Mm}^{3}$ (and live storage capacity of about $1283 \mathrm{Mm}^{3}$ ), it is a multi-purpose dam aimed for providing irrigation water to about 22,000 ha in KRIP besides the other objectives of Kano city water supply (KCWS) and other downstream users. Meanwhile, a hydropower generation project is currently under construction. Tiga dam serves the KRIP via the Ruwan Kanya Reservoir (RKR) downstream of the main canal from Tiga Dam and provides raw water for Kano City.

\subsection{Methodology}

The methodology consists of four steps: (1) defining Sefficiency; (2) data collection; (3) designing the options to be evaluated; and (4) developing case scenarios and sensitivity analyses of results due to varying population growth and climate change.

\subsubsection{Sefficiency (Sustainable Efficiency)}

The Sefficiency framework [26] was used to evaluate the performance of WUSs, by modelling drivers, such as climate change and population growth, and their influences on water resources. A brief description of the methodology is provided here, further details can be found in [10,39]. The structure given in Figure 2 is unchangeable from project to project and shows the water flow path types (WaTs) used to define the terminology presented (with the Usefulness Criterion of Equation (2)) upon which the indicators, such as in Equation (1), can be developed.

$$
\begin{gathered}
\text { MacroE }_{S}=\left[\frac{\mathrm{ET}+\mathrm{NR}+\mathrm{i}(\mathrm{VD}+\mathrm{RP})}{\mathrm{VU}+\mathrm{OS}+\mathrm{PP}-\mathrm{c}(\mathrm{VD}+\mathrm{RP})}\right]_{\mathrm{S}} ; \mathrm{i}+\mathrm{c}=1 \text { with } \mathrm{i}, \mathrm{c} \in\{0,1\} \\
\mathrm{MesoE}_{\mathrm{S}}=\left[\frac{\mathrm{ET}+\mathrm{NR}+\mathrm{i}(\mathrm{RF}+\mathrm{RP})}{\mathrm{VA}+\mathrm{OS}+\mathrm{PP}-\mathrm{c}(\mathrm{RF}+\mathrm{RP})}\right]_{\mathrm{S}} \\
\text { MicroE }_{S}=\left(\frac{\mathrm{ET}+\mathrm{NR}}{\mathrm{VA}+\mathrm{OS}+\mathrm{PP}}\right)_{\mathrm{S}}
\end{gathered}
$$


The subscript ' $s$ ' in Equation (1) stands for the Usefulness Criterion and applies to all the flows within the brackets, e.g., $\mathrm{ET}_{\mathrm{S}}=\mathrm{W}_{\mathrm{qET}}{ }^{*} \mathrm{~W}_{\mathrm{bET}}{ }^{*} \mathrm{ET}$. The useful dimension of a water flow path $\mathrm{X}\left(\mathrm{X}_{\mathrm{S}}\right)$ is derived by using two weights:

$$
\begin{gathered}
\mathrm{X}_{\mathrm{b}}=\mathrm{W}_{\mathrm{bX}}{ }^{*} \mathrm{X} \\
\mathrm{X}_{\mathrm{q}}=\mathrm{W}_{\mathrm{qX}}{ }^{*} \mathrm{X} \\
\mathrm{X}_{\mathrm{s}}=\mathrm{W}_{\mathrm{sX}}{ }^{*} \mathrm{X} \\
\mathrm{W}_{\mathrm{s} \mathrm{X}}=\mathrm{W}_{\mathrm{bX}}{ }^{*} \mathrm{~W}_{\mathrm{qX}}
\end{gathered}
$$

where $\mathrm{W}_{\mathrm{bX}}$ is the beneficial weight of the water flow path $\mathrm{X} ; \mathrm{W}_{\mathrm{qX}}$ is its quality weight; and $\mathrm{W}_{\mathrm{sX}}$ is the usefulness weight. All the weights vary between 0 and 1 with the latter giving the best condition. $X$ can be any flow, such as VA or RF (please refer to Figure 2). Also, the water flow paths (WaPs) and their weights are set within a clearly defined time frame. If all the quality weights are set to 1 , then a quantity-based Sefficiency is given and the analyses can be carried out without water pollution consideration. Such quantitative studies, although popular, do not consider the complexity that water quality brings into management, design and governance of WUSs in an uncertain but real world. Therefore, the author strongly suggests the use of the full Sefficiency model, i.e., with both attributes. The binary parameters ' $\mathrm{i}$ ' and ' $\mathrm{c}$ ' $(\mathrm{i}+\mathrm{c}=1)$ give the input and output efficiencies, respectively, i.e., $\mathrm{i}$ and $\mathrm{c}$ are the inflow and consumptive models. These concepts lead to the definition of macro, meso, and micro-efficiencies, which form a set of integrated indicators that explicitly promote stakeholder involvement in evaluation and design of WUS as presented in Equation (1) with basic water flow types defined in Figure 2. The appearance of one of these before MesoE or MacroE shows the type of indicator. For example, $\mathrm{iE}_{\mathrm{s}}$ is an inflow Sefficiency indicator (i.e., $\mathrm{i}=1$ ), which gives the percentage of total useful inflow which is useful outflow. $\mathrm{cE}_{\mathrm{s}}$ (i.e., $\mathrm{c}=1$ ) provides the percentage of effective consumption that is useful consumption (i.e., $\mathrm{ET}_{\mathrm{s}}+\mathrm{NR}_{\mathrm{s}}$ ). $\mathrm{MacroE}_{\mathrm{s}}$ gives the impact of a WUS on the basin (the main source of water), while MicroE $\mathrm{s}_{\mathrm{s}}$ is about the efficiency of a WUS itself (i.e., without considering its returns). $\mathrm{MesoE}_{\mathrm{s}}$ is between the other two in that it includes return flows in its calculation, i.e., considering the impact of the system on the downstream users, including nature.

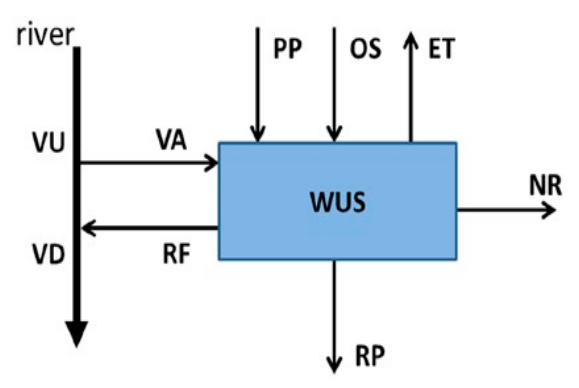

\begin{tabular}{cc}
\hline Variables & Description \\
\hline ET & Evapotranspiration \\
NR & Non-reusable \\
OS & Water from other sources \\
PP & Total precipitation \\
RF & Return flow \\
RP & Potential return (does not return to the main \\
VA & source) \\
VD & Abstracted/applied water from the main source \\
& Volume of water downstream after return flow in \\
VU & the main source \\
& the main source \\
\hline
\end{tabular}

Figure 2. Basic water flow path types (WaTs) of a water use system (WUS) and its description.

The principle of the conservation of mass is one of the central aspects of Sefficiency, meaning that at each junction within the system water balance must be satisfied. Practically, for longer time intervals, this requires that the total outflow falls, say, within five percent of total inflow, because anywhere, including in Nigeria, the accuracy of most of the data has some level of uncertainty. The timescale of the analysis is taken on a yearly basis during which the change in water storage of Tiga dam is assumed to be negligible relative to other annual flows within that period. To use the law of conservation of mass (water balance), WUS is defined by characterizing the associated water flow types (WaTs, shown in Figure 2) and their corresponding two attributes (quality and benefits). Water flow Paths (WaPs) are actual or real water flows in a system under analysis. WaTs are types or classes of inflow and outflow that must be expanded into WaPs because a water type can lead to zero, one, or more than one flow 
path. Accounting for all the nine WaTs shown and defined in Figure 2 is very crucial for transparency and completeness in achieving sustainable water management.

Sefficiency is a powerful framework in the analysis of /for policies of WUSs, explicitly integrating environmental, societal, and economical dimensions of policies. This brings transparency into water accounting/balance, pollution sources/distributions, and benefit producers/users by employing a comprehensive set of WaTs and their Usefulness Criteria which promote involvement of many types of stakeholders and reveals two important classes of input and output efficiencies. The foundational interconnectedness among common aspects of diverse systems is secured through a universal law that ensures proper application of Sefficiency to any location, scale and level in a specific period of time. It promotes robust policies for adaptation to almost all the drivers of change, particularly climate change, through systemic and complete integration of the differentials of water quantity, quality and benefits.

\subsubsection{Data Collection}

A wide range of study methods, including semi-structured interviews, a case study of the irrigation project, personal correspondence, field visits, observation and secondary data were used. Data was collected from previous project documents, published peer-reviewed papers, interviews with stakeholders, plausible reasoning, and calculations. Basic data collected include hydrological and hydraulic data, and water demand, uses, and consumption patterns. Data on existing water allocation practices and wastewater collection and treatment are lacking in the study area, as is the case with many developing countries [40]. The analysis also accounts for abstractions for various uses such as irrigation and domestic through indirect ways using information on urban water supply, crop water demand, cropping pattern, and cropped area available. Data for KCWS (2014-2016) was obtained from Kano State water board (KNSWB). Estimating the contribution of various factors affecting water balance (rainfall, seepage from canals, percolation from farmers' fields, groundwater abstraction) in the study area is challenging. However, crop evapotranspiration requirements were estimated using CROPWAT 8.0 [41] and other flows were documented in reports (Table 1) and papers [42].

Quality weights were derived from previous project documents. Monthly effluent discharge monitoring reports for industries were obtained from pollution control laboratory of Kano state ministry of environment. Management's and farmers' perception of the beneficial use of water (beneficial weights) was gathered through stratified random sampling and interviewed in March-April 2016 and followed up in March-April 2017. Other stakeholders contacted were management of KNSWB, Kano city residents, industrialists, and consultants.

Table 1. Dry-season flows in the Hadejia River (February-March 1998).

\begin{tabular}{ll}
\hline Flow Component & Volume Flow Rate Q $\mathbf{~ M m}^{\mathbf{3}} /$ year) \\
\hline Irrigation canal to Ruwan Kanya Reservoir & 618.11 \\
Inflow to Ruwan Kanya Reservoir & 400.51 \\
Spill from Ruwan Kanya Reservoir to Kano River & 85.15 \\
Outflow from KRIP into Hadejia River & 245.98 \\
Water usage by KRIP \& evaporation Ruwan Kanya Reservoir & 286.98 \\
Kano River near Bagauda dam, downstream & 302.75 \\
Smaller Tiga outlets and by-pass outlet from irrigation canal & 217.60 \\
Total releases from Tiga dam & 835.70 \\
Releases from Tiga dam in Hadejia River & 549.73 \\
\hline
\end{tabular}

Source: [43].

\subsubsection{Options to be Evaluated}

The WUSs under study comprised of subsystems that serve the purposes of agricultural, environmental, and urban water supply. The objective of this evaluation was to estimate the performance and challenges of different WUS in KRB until 2050. Options considered for evaluation are 
the impacts of population growth and climate change on performances of the two principal water users in the basin, i.e., KRIP model (M1) and Kano River model (M2), taking into account the environmental flows. For M1, WUS is defined as KRIP including the main canal and RKR, and M2 is defined as the Kano River, starting from the Tiga dam until downstream just before Hadejia River (Figure 2). Figure 3 depicts the typical schematic of the Kano River basin showing the M1 and M2.

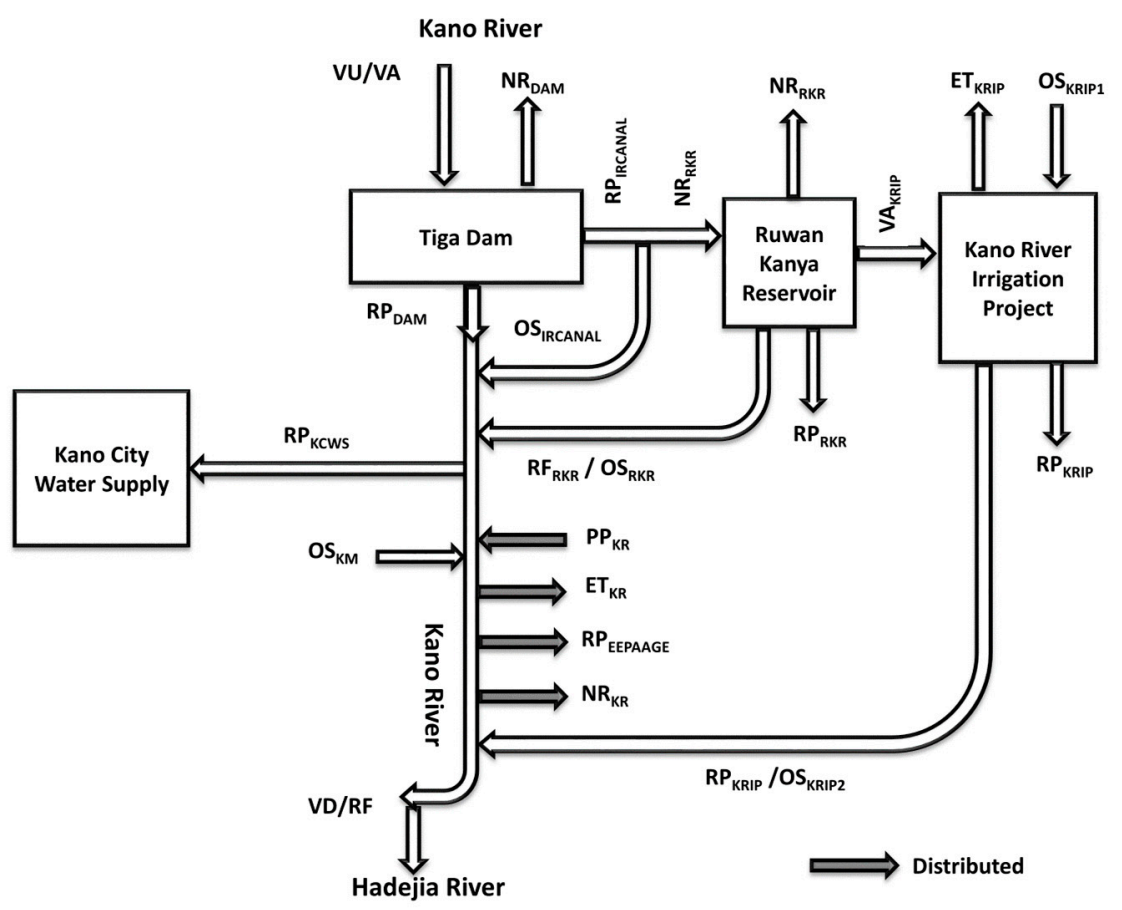

Figure 3. Typical schematic of Kano River as the WUS (M2).

The following water balance equation (Equation (3)) should be satisfied as depicted in Figure 3 for Kano River:

$$
\begin{aligned}
\mathrm{VU}+\mathrm{PP}_{\mathrm{KR}}+\mathrm{OS}_{\text {IRCANAL }}+\mathrm{OS}_{\mathrm{KM}}+\mathrm{OS}_{\mathrm{KRIP} 2}+\mathrm{OS}_{\mathrm{RKR}} \\
\\
=\mathrm{ET}_{\mathrm{KR}}+\mathrm{NR}_{\mathrm{DAM}}+\mathrm{NR}_{\mathrm{KR}}+\mathrm{NR}_{\mathrm{RKR}}+\mathrm{RP}_{\text {IRCANAL }}+\mathrm{RP}_{\mathrm{KCWS}}+\mathrm{RP}_{\mathrm{SEEPAGE}} \\
+\mathrm{RP}_{\mathrm{DAM}}+\mathrm{VD}
\end{aligned}
$$

where $\mathrm{VU}=$ volume of water upstream of Tiga dam; $\mathrm{PP}_{\mathrm{KR}}=$ precipitation over Kano River; $\mathrm{OS}_{\mathrm{IRCANAL}}$ = smaller Tiga outlets and by-pass outlets from irrigation canal; $\mathrm{OS}_{\mathrm{KM}}=$ wastewater from Kano Metropolis into Kano River; $\mathrm{OS}_{\mathrm{KRIP} 2}=$ return flows from KRIP; $\mathrm{OS}_{\mathrm{RKR}}=$ spills from RKR to Kano River; $\mathrm{ET}_{\mathrm{KR}}=$ non-beneficial ET from Kano River; $\mathrm{NR}_{\mathrm{DAM}}=$ evaporation loss and seepage from Tiga dam; $\mathrm{NR}_{\mathrm{KR}}=$ evaporation loss from Kano River; $\mathrm{NR}_{\mathrm{RKR}}=$ consumptive uses by RKR; $\mathrm{RP}_{\mathrm{IRCANAL}}=$ irrigation canal to RKR; $R_{\text {SEEPAGE }}=$ seepage through Kano River bed; $R P_{K C W S}=$ water applied to KCWS; $\mathrm{RP}_{\mathrm{DAM}}=$ spills from Tiga dam; $\mathrm{VD}=$ water downstream just before confluence with Challawa River to form Hadejia River

Because of its importance, let us define the terms of Equation (3) with respect to Figure 3. It is important to note that some flow paths may have similar influence on the system depending on whether it is inflow or outflow. For example, both $\mathrm{OS}_{\text {IRCANAL }}$ and RP $\mathrm{DAM}_{\mathrm{D}}$ are inflow, however, in Sefficiency terms they have different terminologies. Another important thing is that this paper only deals with analysis of Kano River as a WUS, for a more in depth analysis of KRIP as a standalone WUS, the reader should refer to [10].

$\mathrm{VU}$ is the volume of water upstream of Tiga dam before abstraction in the main source. VA is the abstracted/applied water from the main source, in this case, it is the total average annual inflow into Tiga reservoir. Precipitation over Kano River, $\mathrm{PP}_{\mathrm{KR}}$, is the volume of water retained in Kano 
River as a result of local rainfall during the wet season. OS (other sources) is the inflow from sources other than the main source, which in this case, was expanded into four flow paths. Water spills into Kano River from the main irrigation canal through smaller Tiga outlets and by-pass outlets is termed as OS IRCANAL. While $\mathrm{OS}_{\mathrm{KM}}$ is the volume of wastewater from Kano Metropolis into Kano River, OS $_{\text {RKR }}$ is the volume of spills from Ruwan Kanya Reservoir into Kano River. OS KRIP2 $_{\text {is }}$ the volume of return flows from irrigated fields through drainages called Maraga into Kano River, which often contains chemicals (fertilizers, insecticides, and herbicides) that render the water polluted. $\mathrm{ET}_{\mathrm{KR}}$ is the non-beneficial consumption in Kano River and the surrounding flood plain due to the presence of Typha grass and other weeds. NR is the other outflow that is non-reusable, including, for example, evaporation, "virtual water" embodied in various products manufactured within the system under analysis, and other processes. This was expanded into three flow paths. $\mathrm{NR}_{\mathrm{DAM}}$ is the volume of evaporation loss and seepage from Tiga dam, while $\mathrm{NR}_{\mathrm{KR}}$ is the volume of evaporation loss from Kano River. $\mathrm{NR}_{\mathrm{RKR}}$ is that part of inflow to main irrigation canal that is supplied to Ruwan Kanya Reservoir for the purpose of irrigation at KRIP. RP is the water returned from a WUS to the environment outside of it (not returned to its source of abstraction), which could be expanded into the following: RP IRCANAL, $\mathrm{RP}_{\mathrm{KCWS}}, \mathrm{RP}_{\mathrm{SEEPAGE}}$ and $\mathrm{RP}_{\mathrm{DAM}}$. Part of the water supplied to irrigation canal flows back into Kano River and is termed $\mathrm{RP}_{\text {IRCANAL }}$. $\mathrm{RP}_{\mathrm{KCWS}}$ is the volume of water supplied to KCWS. $\mathrm{RP}_{\text {SEEPAGE }}$ is the volume of water seeping through Kano River bed. There is a spill from Tiga reservoir into Kano River termed as $\mathrm{RP}_{\mathrm{DAM}}$. VD is the volume of water downstream just before confluence with Challawa River to form Hadejia River.

It is important to note that VD is assumed to be the same as RF, and VU is the same as VA. It makes sense because the WUS under analysis is part and parcel of the river supplying the water. The following subsections give details of the volumes of Kano River water flow paths, and their quality and beneficial weights.

\section{Water Flow Paths (WaPs) Quantities}

PP was estimated as $5 \mathrm{Mm}^{3}$ assuming a direct relationship between the flood plain area (having an average width of $90 \mathrm{~m}$ ) and average annual rainfall of $884 \mathrm{~mm}$. PP is for the river only, but not for the irrigated area which was incorporated in CropWat. Average annual evaporation loss $\left(\mathrm{NR}_{\mathrm{DAM}}\right)$ of $214 \mathrm{Mm}^{3}$ [44] was used which compares well with $182 \mathrm{Mm}^{3}$ at $50 \%$ storage [42]. NR $\mathrm{DAM}_{\text {is distinct }}$ from ET (non-beneficial consumption in Kano River due to the presence of Typha grass and other weeds) which was calculated as $4 \mathrm{Mm}^{3}$ using reference evapotranspiration, $\mathrm{ET}_{\mathrm{O}}=5.23 \mathrm{~mm} /$ day calculated for KRIP. Actual evapotranspiration $\left(\mathrm{ET}_{\mathrm{c}}\right)$ was then computed adopting FAO-56 approach. The pan evaporation is related to the reference evapotranspiration by an empirically derived pan coefficient [45]. Moreover, $\mathrm{NR}_{\mathrm{KR}}$ was calculated using a relation of $\mathrm{NR}_{\mathrm{DAM}}$ and its area to be $62 \mathrm{Mm}^{3}$. $N_{R K R}$ is the part of inflow to main irrigation canal consumptively use by RKR estimated as $400 \mathrm{Mm}^{3}$. OS was expanded into four flow paths corresponding to smaller Tiga outlets and by-pass outlets from the irrigation canal, spills from RKR, return flows from KRIP, and wastewater flows from Kano Metropolis designated as $\mathrm{OS}_{\text {IRCANAL, }} \mathrm{OS}_{\mathrm{RKR}}, \mathrm{OS}_{\mathrm{KRIP}}$, and $\mathrm{OS}_{\mathrm{KM}}$ respectively. $\mathrm{OS}_{\mathrm{IRCANAL}}, \mathrm{OS}_{\mathrm{RKR}}$, and $\mathrm{OS}_{\mathrm{KRIP}}$ were measured to be 218,85 , and $246 \mathrm{Mm}^{3}$, respectively. Domestic wastewater flows (OS $\mathrm{OSM}_{\mathrm{KM}}$ was determined from domestic water uses [46] as $5.3 \mathrm{Mm}^{3}$ assuming a non-consumptive fraction of 0.8 (fraction of total wastewater).

$\mathrm{RP}$ was also expanded into four flow paths, namely, $R P_{\text {IRCANAL }}, \mathrm{RP}_{\mathrm{KCWS}}, \mathrm{RP}_{\mathrm{SEEPAGE}}$, and $\mathrm{RP} \mathrm{DAM}_{\mathrm{DAM}}$. $\mathrm{RP}_{\mathrm{IRCANAL}}$ corresponds to that part of the water supplied to irrigation canal measured as $218 \mathrm{Mm}^{3}$, which flows back to Kano River. $\mathrm{RP}_{\mathrm{KCWS}}$ is the amount of water applied to KCWS estimated as $44.2 \mathrm{Mm}^{3}$ according to data obtained from planning, research, and statistics division of KNSWB. $\mathrm{RP}_{\text {SEEPAGE }}$ is the volume of seepage through the Kano River bed by assuming the groundwater level rise due to river bed recharge of $127 \mathrm{~cm}$ [47] calculated to be $39 \mathrm{Mm}^{3}$. Moreover, based on the discussion with the management of Hadejia-Jama'are River Basin Development Authority (HJRBDA), there is a spill from Tiga reservoir into Kano River estimated as $4 \mathrm{Mm}^{3}$. VD is the amount of water downstream 
of Kano River precisely just before the confluence of the Kano and Challawa Rivers to form Hadejia River. Practically, VD is the amount of water that is available for downstream users and the minimum flow requirement of the river estimated as $411 \mathrm{Mm}^{3}$. Similarly, RF is assumed to be equals to VD following the reason stated earlier. Due to the importance of environmental flows and downstream users, a minimum of $135 \mathrm{Mm}^{3}$ per year is guaranteed as far as this study is concerned. VU is the total volume of water upstream of Tiga dam estimated at $836 \mathrm{Mm}^{3}$. Similarly, VA is the total average annual inflow into Tiga reservoir estimated at $836 \mathrm{Mm}^{3}$.

\section{Setting Water Quality and Beneficial Weights}

The quality weights of $\mathrm{OS}_{\text {IRCANAL }}, \mathrm{PP}, \mathrm{RP}_{\mathrm{DAM}}, \mathrm{RP}_{\text {IRCANAL }}, \mathrm{VA}$, and VU are considered basically the same. These flow paths are essentially the same water and hence have the same quality. The quality weights for each of these WaPs ( $W_{\mathrm{q} x}$ values) are fixed at 1 . Similarly, $\mathrm{ET}_{\mathrm{KR}}, \mathrm{NR}_{\mathrm{KR}}$, and $\mathrm{NR}_{\mathrm{DAM}}$ are set at 1 because possibly water evaporated from soil surface or transpired from the stoma of leaves are among the purest one can have. However, the quality of $\mathrm{NR}_{\mathrm{RKR}}, \mathrm{OS}_{\mathrm{RKR}}, \mathrm{OS}_{\mathrm{KRIP2}}$, and $\mathrm{OS}_{\mathrm{KM}}$ are reduced to 0.8 due to anthropogenic and agricultural activities in Kano city, and around RKR and KRIP. The water quality of $\mathrm{RP}_{\mathrm{KCWS}}$ is the combination of $\mathrm{OS}_{\mathrm{RKR}}$ and $\mathrm{OS}_{\text {IRCANAL }}$ RP $\mathrm{SEEPAGE}_{\text {, }}$, and VD are practically the same water and their quality weights are fixed at 0.8 .

The beneficial weights of all the flow paths except $\mathrm{ET}_{\mathrm{KR}}, \mathrm{NR}_{\mathrm{KR}}$, and $\mathrm{NR}_{\mathrm{DAM}}$ are fixed to 1, while $W_{\mathrm{bNRDAM}}$ and $\mathrm{W}_{\mathrm{bNRKR}}$ are set to 0.3 . The latter weights suffer due to non-beneficial nature of the flow path (i.e., evaporation). Although undesired in the system, evaporation is an essential part of the water cycle. $W_{\text {bETKR }}$ is set to 0.15 due to non-beneficial ET consumption (15\%) as result of Typha grass and other weeds present in Kano River. Summary of WaP quantities, quality, and beneficial weights for M1 and M2 with their percentage changes relative to reference for all the scenarios considered are shown in Supplementary Materials. Reasons for percentage changes are also presented.

\subsubsection{Developing Case Scenarios and Sensitivity Analyses}

To develop future water allocation scenarios for KRB, possible factors influencing future water uses were identified and quantified. Case scenarios were developed based on two critical drivers of change: (i) population growth; and, (ii) climate change. Both population growth and climate change have an impact on increasing water demand, while climate change reduces water supply. The differences among the various scenarios were considered against the baseline or reference scenarios.

First, reference population and growth rate were characterized upon which the future projections were based. Projections of the future population based on the 2006 census [48] of 2.8 million and growth rate of 3.5\% for Kano metropolis was carried out for 2017, 2025, 2035, and 2050. The recent United Nations Department of Economic and Social Affairs (UN DESA) figure [49] is comparable to that of National Population Commission (NPC), having a percentage difference of 3\% (Figure 4). Per capita consumption for water (future urban demand) was projected using the standard per capita consumption adopted by [50] for domestic (based on different housing types and incomes), commercial, and industrial (Table 2). Based on these assumptions, water demand was estimated for 2017 and projected for 2025, 2035, and 2050 (Figure 4). It is important to note that $50 \%$ of water demand for KCWS was abstracted from Kano River, i.e., 9\% increase relative to $41 \%$ in 2017 . The remaining comes from other resources like groundwater. Similarly, irrigation requirements were also estimated (Figure 5). For climate change, increase in rainfall in the study area was reported in [38], however, percentage increase in rainfall, temperature and evaporation was based on [51]. Outputs from projections done by [42] from an ensemble of 38 Global Circulation Model (GCM) runs under the median $\mathrm{A}_{1 \mathrm{~B} \mathrm{CO}_{2}}$ emission scenarios was used in this study. In all the projections, the rate of change is uniform and increase is linear (steady). Temperatures show a steady increase of $0.035^{\circ} \mathrm{C}$ per year and $1.2{ }^{\circ} \mathrm{C}$ from 2017 to 2050; on average $2.1^{\circ} \mathrm{C}$ (4\% increase) by 2050. Precipitation shows a marginal upward trend by $12.4 \mathrm{~mm}$ which is just $1.4 \%$ difference by 2050 relative to the reference. Evapotranspiration show a steady increase of $105 \mathrm{~mm}$ relative to reference (5.3\%) by 2050 (Table 3). 


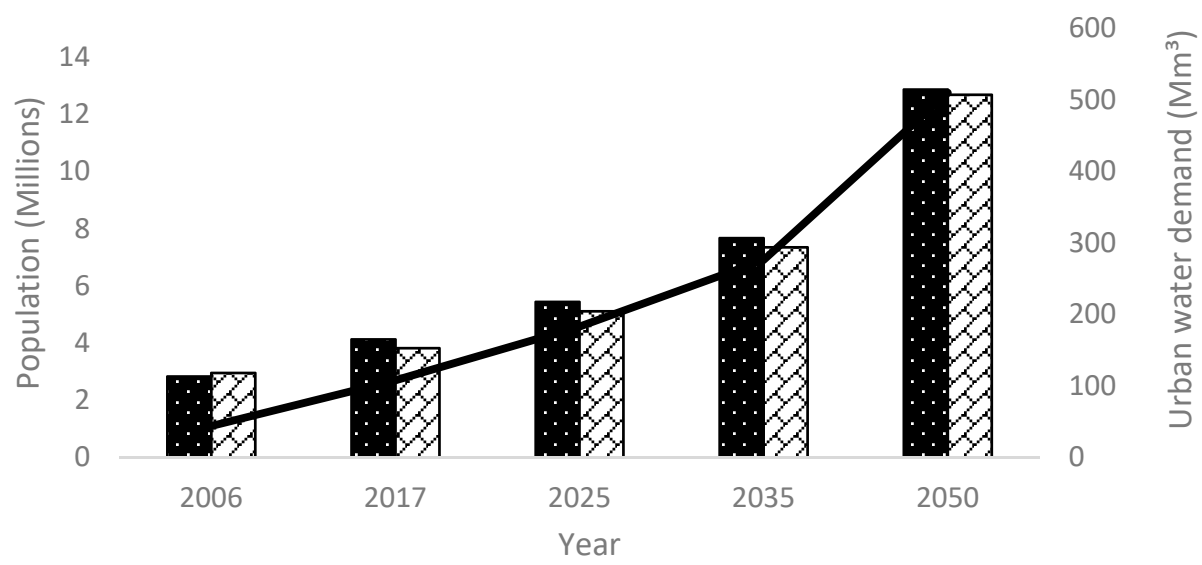

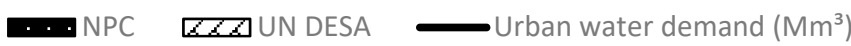

Figure 4. Population and water demand projection of Kano Metropolis.

Table 2. Estimated present and projected water demand for Kano city.

\begin{tabular}{|c|c|c|c|c|}
\hline \multirow[b]{2}{*}{ Consumer Demand } & 2017 & 2025 & 2035 & 2050 \\
\hline & $\begin{array}{l}\text { Demand } \\
\left(\mathrm{Mm}^{3}\right)\end{array}$ & $\begin{array}{l}\text { Estimated Demand } \\
\qquad\left(\mathrm{Mm}^{3}\right)\end{array}$ & $\begin{array}{l}\text { Estimated Demand } \\
\qquad\left(\mathrm{Mm}^{3}\right)\end{array}$ & $\begin{array}{c}\text { Estimated Demand } \\
\left(\mathrm{Mm}^{3}\right)\end{array}$ \\
\hline low density & 8.14 & 10.72 & 16.80 & 28.15 \\
\hline medium density & 6.79 & 12.50 & 22.68 & 42.22 \\
\hline high density & 33.18 & 61.14 & 110.86 & 206.41 \\
\hline Standpipes & 3.65 & 3.65 & 3.65 & 7.3 \\
\hline Total Domestic & 51.76 & 88.02 & 153.99 & 283.97 \\
\hline Industries (25\% domestic) & 12.94 & 22.01 & 38.51 & 71.18 \\
\hline Institutions (10\% domestic) & 5.18 & 8.76 & 15.33 & 28.47 \\
\hline $\begin{array}{l}\text { Total excluding unaccounted } \\
\text { for water }\end{array}$ & 69.87 & 118.99 & 208.05 & 383.62 \\
\hline$\%$ of unaccounted for water & $54 \%$ & $54 \%$ & $33 \%$ & $33 \%$ \\
\hline Total including losses & 107.68 & 182.87 & 276.31 & 509.91 \\
\hline
\end{tabular}

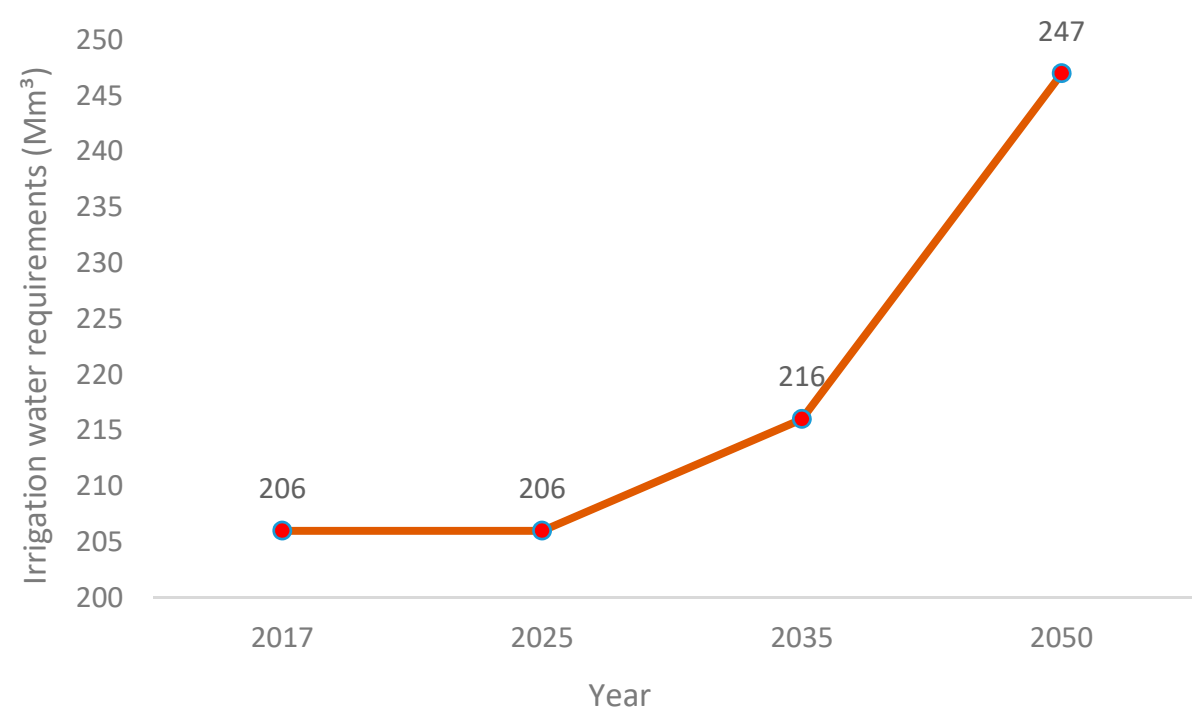

Figure 5. Present and projected water demand for Kano River Irrigation Project (KRIP). 
Table 3. Percentage changes for temperature, precipitation and ET and its projection referenced to 2017.

\begin{tabular}{ccccccc}
\hline \multirow{2}{*}{ Year } & Temperature & Temperature & Precipitation & Precipitation & ET & ET \\
\cline { 2 - 7 } & Change $\%$ & ${ }^{\circ} \mathbf{C}$ & Change $\%$ & $\mathbf{( m m )}$ & \% Change & $(\mathbf{m m})$ \\
\hline 2017, ref & 0 & 27.9 & 0 & 884.00 & 0 & 1995 \\
2025 & 1 & 28.2 & 0.82 & 891.29 & 1.3 & 2020 \\
2035 & 2 & 28.6 & 1.06 & 893.35 & 2.9 & 2052 \\
2050 & 4 & 29.1 & 1.41 & 896.45 & 5.3 & 2100 \\
\hline
\end{tabular}

The population scenario was developed by keeping a variable of a parameter related to water demand volume (based on different percentages of supply) and keeping a constant of the parameter related to climate change (temperature and precipitation). Similarly, the climate change scenario was developed by keeping a variable of a parameter related to climate change and keeping a constant of the parameter related to the water demand volume. The projected change in rainfall and temperature were incorporated in the various WaPs for the two models keeping the population constant. To investigate the combined impact of climate change and population growth, the projected change in population, rainfall, and temperature with associated change in ET were incorporated into WaPs all together, allowing a quantification of the impact of climate change and population growth simultaneously.

Generally, we applied two models designated as M1 and M2 for KRIP and Kano River model, respectively. We also defined 3 sub-models, namely, P, C, and B for population, climate change, and the duo (population plus climate change) respectively. The appearance of one of $\mathrm{P}, \mathrm{C}$, or B after M1 or M2 shows the type of scenario. For example, M1P means KRIP model under population impact. These are further expanded taking account the projected year as 1, 2, and 3 for 2025, 2035, and 2050, respectively, while 0 represents the reference year, i.e., 2017. For instance, M1P0 refers to KRIP model under reference year while M1P1 refers to KRIP model under population impact in 2025. The same procedure was applied to the climate change and the duo (population plus climate change) scenarios. Consequently, we have M1C1 and M1B1, and so on and so forth. A spreadsheet-based application using Microsoft Excel was developed to automatically compute different Sefficiency and generate their graphs. Other files automatically calculate the percentage changes in quantities of different scenarios stating the reasons for the changes and assumptions made.

All the performances of the two systems were compared based on the same spatial boundary with Kano city (Figure 1). Therefore, all scenarios were assumed to be in the position where the reference is currently. This includes the position of the households and the agriculture site. All the scenarios were also compared based on the same temporal boundary with the situation in reference year, i.e., 2017.

\section{Results and Discussion}

Results of the systems evaluations with Sefficiency were presented showing the performances of M1 and M2 at different levels and the differences between the scenarios. Also, classical efficiency (CE) was obtained in all M1 scenarios. The linguistic discussion that follows uses the same procedure as in [10] relative to the difference in percentage points. Sefficiency values within $2 \mathrm{pp}$ can be considered equal and significant or high if it is greater than $5 \mathrm{pp}$. If the difference is closer to 5 , the greater is considered slightly higher. In general, the results are complex as one expects for a system with so many variables and parameters. This application shows the following possible results as presented in the following subsections. It is worth mentioning that in all $\mathrm{M} 2$ results, $\mathrm{MacroE}_{\mathrm{s}}$ and $\mathrm{MesoE}_{\mathrm{s}}$ values are equal. Hence iMesoE $E_{s}$ or $\mathrm{iMacroE}_{\mathrm{s}}$ and $\mathrm{cMesoE}_{\mathrm{s}}$ or $\mathrm{cMacroE}_{\mathrm{s}}$ are represented by $\mathrm{iE}_{\mathrm{s}}$ and $\mathrm{cE}_{\mathrm{s}}$ respectively. The difference in percentage points between scenarios gives the magnitude of the impact it has on performance. The higher the number, the bigger the impact. 


\subsection{Sefficiency Results Based on Population Growth}

\subsubsection{Sefficiency for M1P}

Both inflow and consumptive meso-efficiency ( $\mathrm{iMeso}_{\mathrm{s}}$ and $\mathrm{cMeso}_{\mathrm{s}}$ ) values for M1P1, M1P2, and M1P3 scenarios go down significantly (i.e., greater than $5 \mathrm{pp}$ ) compared to M1P0. This suggests that useful outflow per unit of useful inflow decreases, and useful consumption per unit of effective consumption decreases relative to the reference.

The $\mathrm{cMesoE}_{\mathrm{s}}$ for M1P0 (55\%) shows better performance results of Sefficiency (Figure 6). The highest difference occurs between M1P0 and M1P3, making the relative consumptive impact of M1P3 on the WUS rather high (Figure 7a,d). The impacts are highest when VA and ET are increased by $20 \%$, indicating that due to high increase in population, much more land is required for planting and consequently generating more pollution. Hence, population growth resulted in decreasing the performance of KRIP due to pollution generated because of increased agricultural activities in farmlands. For iMesoE $E_{s}$, the difference between inflow efficiency of all the scenarios have the same value, i.e., $10 \mathrm{pp}$. The useful outflow compared with useful inflow for the WUS and basin is significantly lower (Figure 7a,d).

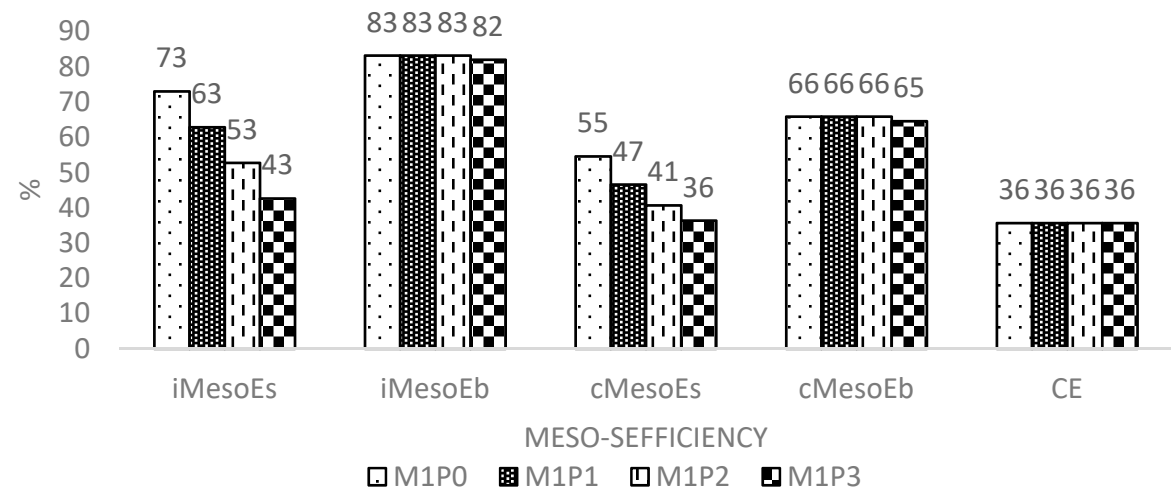

Figure 6. Sefficiency for M1P.

Even though $\mathrm{W}_{\mathrm{b}}$ stays the same in all the different scenarios, quantities change up to $20 \%$, but the quantitative efficiencies $\left(E_{b}\right)$ do not change. In reality, other efficiency terms that do not consider quality in their equations show the same efficiency although quality changes (like $\mathrm{CE}$, see Figure 6). In other words, although the quantities change, their fractions remain relatively the same. In these scenarios, water quality has an influence on the performance of KRIP under the influence of population growth.

Another interesting result is the famous CE that gives the worst efficiency for all the scenarios. For M1, very low values of CE were obtained in all the scenarios. This is because CE does not consider issues such as water reuse (return flows), distinction between total water use and water consumption, effect of use location in an irrigated district or a basin and water quality. However, these issues are particularly important for water management especially in the context of water scarcity. For example, efficiency increases when part of the irrigation return flow is recycled through the hydrological system [39]. 


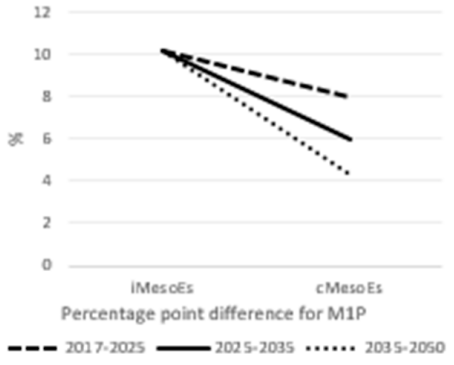

(a)

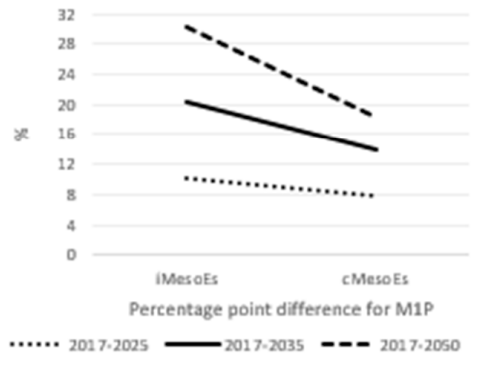

(d)

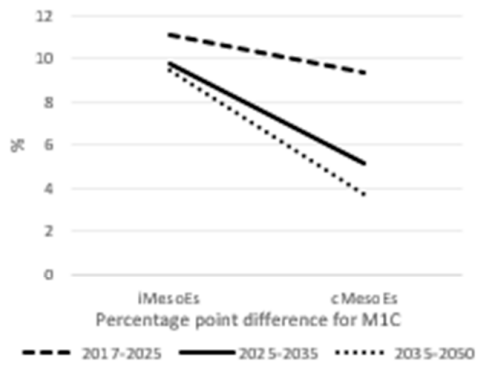

(b)

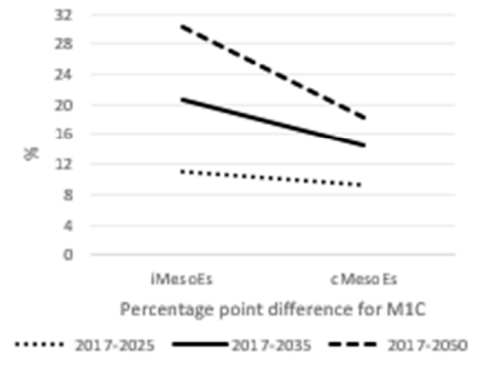

(e)

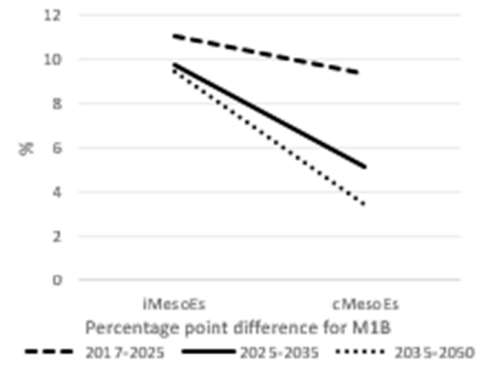

(c)

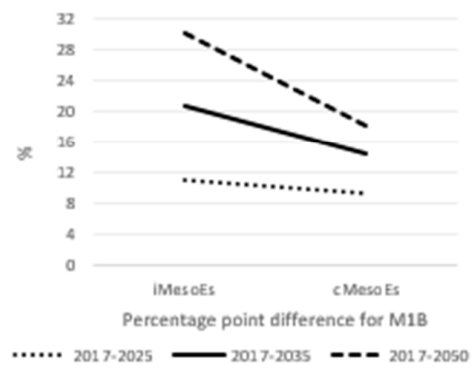

(f)

Figure 7. Percentage point differences between M1 scenarios. (a) percentage point difference for M1P; (b) percentage point difference for M1C; (c) percentage point difference for M1B; (d) percentage point difference for M1P with respect to 2017; (e) percentage point difference for M1C with respect to 2017; (f) percentage point difference for M1B with respect to 2017.

\subsubsection{Sefficiency for M2P}

Both $\mathrm{iE}_{\mathrm{s}}$ and $\mathrm{cE}_{\mathrm{s}}$ values for M2P1, M2P2, and M2P3 scenarios go down significantly compared to M2P0. This suggests that useful outflow per unit of useful inflow decreases, and useful consumption per unit of effective consumption decreases relative to the reference.

The $\mathrm{cE}_{\mathrm{s}}$ for $\mathrm{M} 2 \mathrm{P} 0$ show better performance at both levels (Figure 8). The highest difference occurs between $\mathrm{M} 2 \mathrm{P} 0$ and $\mathrm{M} 2 \mathrm{P} 3$, making the relative consumptive impact of $\mathrm{M} 2 \mathrm{P} 3$ on the basin (and both WUS and the basin in case of Meso) rather high (refer to Figure 9a,d). The impacts are highest when the applied water to KCWS, return flow from KRIP, and wastewater from Kano Metropolis increased by more than $500 \%, 15 \%$, and $200 \%$ respectively, and the volume of water downstream decreased by $50 \%$. This indicates that due to the high increase in population, much more water is required for urban water supply (and hence generating more wastewater due to anthropogenic and agricultural activities) thereby decreasing the quantity and quality of water downstream. Hence, population growth results in decreasing the performance of Kano River.

The lowest difference happened between $\mathrm{iE}_{\mathrm{s}}$ for M2P2 and M2P3 (Figure 9a,d). The useful outflow compared with useful inflow for the basin (or WUS and basin) are slightly higher than M2P3, while the other two show significantly higher values (i.e., between M2P0 and M2P1, and M2P1 and M2P2). This happened with a reduction of $35 \%$ in VD and increase of $84 \%, 60 \%$, and $10 \%$ in applied water to KCWS, wastewater from Kano Metropolis, and return flow from KRIP, respectively.

For the M2P case, high levels of water abstraction and useful consumption values are dominant factors. A minimum value of flow in the river (VD) is required by law, while water supply through RP and NR are highly desired for KCWS and KRIP, respectively. However, in 2025 the Usefulness Criterion " $s$ " for $\mathrm{RP}_{\mathrm{KCWS}}(0.7)$ and $\mathrm{NR}_{\mathrm{RKR}}(0.7)$ are higher than $\mathrm{VD}(0.6)$, meaning that minimum flow requirement of the river is less useful than the water allocated to KCWS and KRIP. This is the case in all the other scenarios.

The $\mathrm{E}_{\mathrm{b}}$ does not change even though quantities change up to $500 \%$ because $\mathrm{W}_{\mathrm{b}}$ stays the same. This agrees with other efficiency terms that do not have quality in their equations show the same 
efficiency although quality changes (see Figure 6 above). In other words, although the quantities change, their average fractions remain the same. This shows that beneficial weights are dominant variable in this case. Considering these scenarios, water quality has an influence on the performance of Kano River under the influence of population growth.

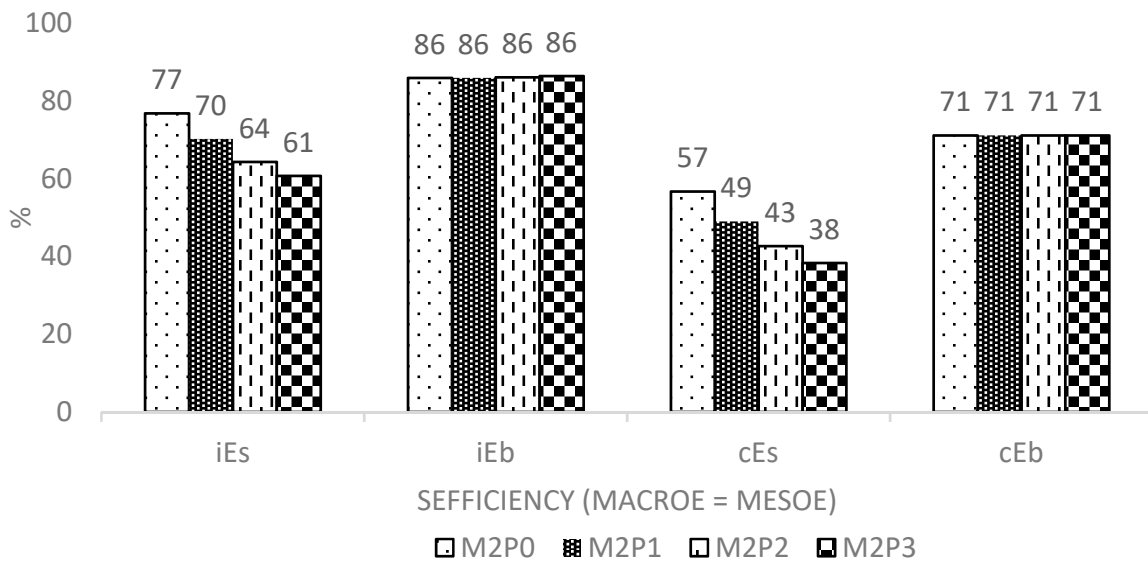

Figure 8. Sustainable efficiency (Sefficiency) for M2P.

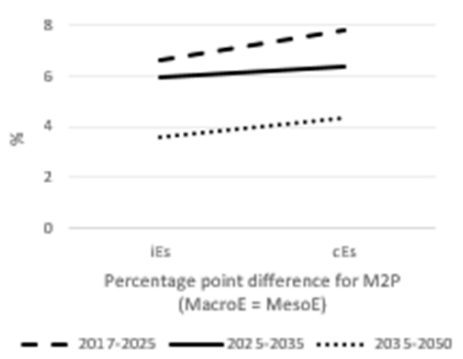

(a)

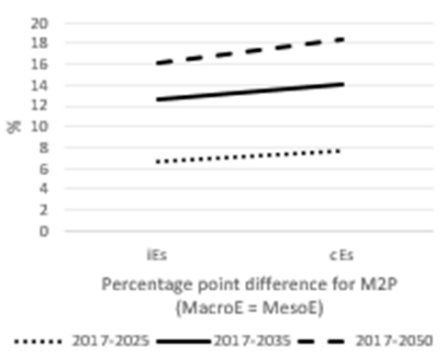

(d)

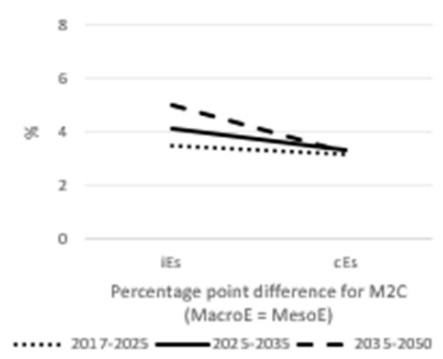

(b)

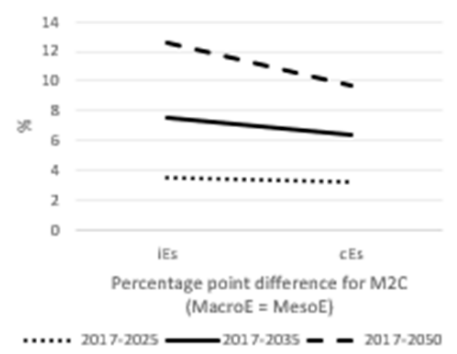

(e)

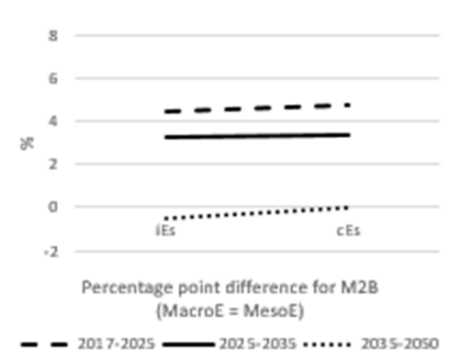

(c)

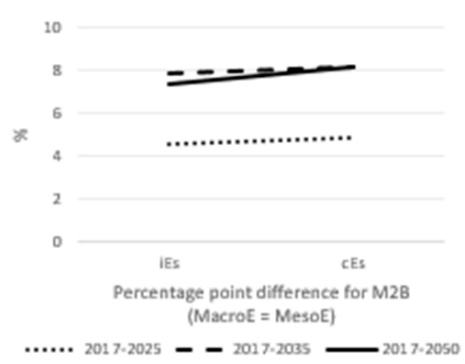

(f)

Figure 9. Percentage point differences between the M2 scenarios. (a) percentage point difference for M2P; (b) percentage point difference for M2C; (c) percentage point difference for M2B; (d) percentage point difference for M2P with respect to 2017; (e) percentage point difference for M2C with respect to 2017; (f) percentage point difference for M2B with respect to 2017.

\subsection{Sefficiency Results Based on Climate Change}

\subsubsection{Sefficiency for M1C}

Both $\mathrm{iMesoE}_{\mathrm{s}}$ and $\mathrm{cMeso}_{\mathrm{s}}$ values for M1C1, M1C2, and M1C3 scenarios go down significantly compared to $\mathrm{M} 1 \mathrm{C} 0$, suggesting that useful outflow per unit of useful inflow decreases, and useful consumption per unit of effective consumption decreases relative to the reference.

The $\mathrm{cMesoE}_{\mathrm{s}}$ for M1C0 shows better performance results (Figure 10). The highest difference is between M1C0 and M1C3, making the relative consumptive impact of M1C3 on the WUS and 
basin rather high (Figure $7 \mathrm{~b}, \mathrm{e}$ ). The impacts are highest when ET increases by 5.3\%, indicating higher evapotranspiration due to temperature rise. Hence, the rise in temperature decreases the performance of KRIP. However, considering an increase in ET-a crucial water-flow path for agricultural systems - and having in mind that it is linearly proportional to yield [52], one would expect an increase in the performance instead of decreasing. While evapotranspiration increases, so does the applied water containing chemicals (fertilizers and pesticides) thereby generating more pollution and hence the decrease in performance. This underscores the fact that focusing on one flow can totally miss a proper water management and design policy. For iMesoEs, the difference between inflow efficiency values for all the scenarios show significant changes (Figure $7 \mathrm{~b}, \mathrm{e}$ ). The useful outflow compared with useful inflow for the WUS and basin of $\mathrm{M} 1 \mathrm{C}$ is significantly lower.

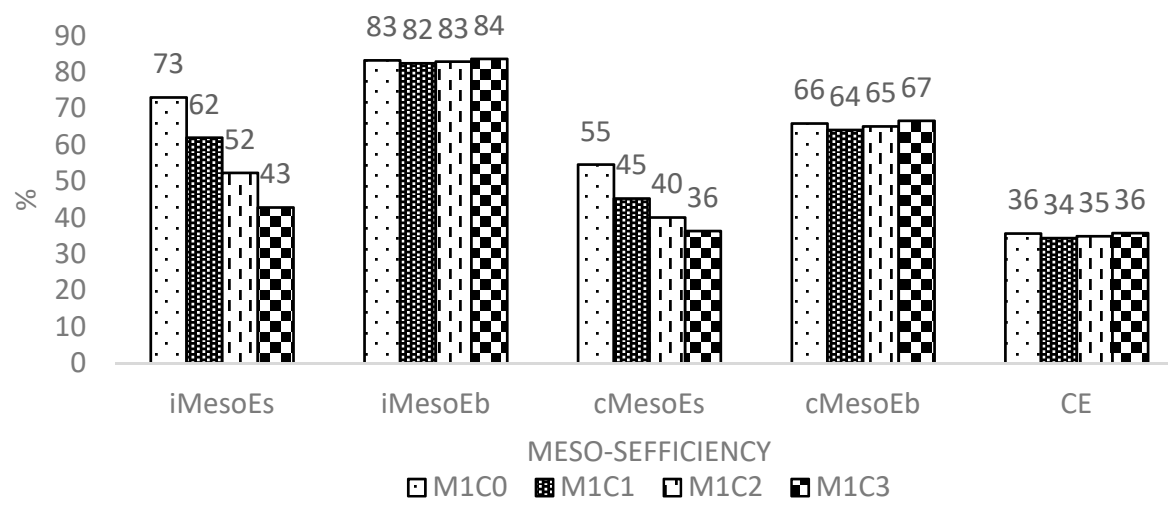

Figure 10. Sefficiency for M1C.

Unlike full inflow and consumptive meso-efficiency, $\mathrm{E}_{\mathrm{b}}$ values for climate change show increasing trends, i.e., the performances change across the scenarios with a maximum of 3 pp in 2050. According to our assumptions, the relative quantity changes are very small, consequently performance increases happened because water quality is not considered (in other words assuming the quality weight of water to be 1) and relative quantities remain the same while beneficial consumption $(\mathrm{ET}+\mathrm{NR})_{\mathrm{b}}-$ mainly ET-increases. In the same manner, CE also started to show an increasing trend. In these scenarios, global warming has more influence on KRIP than population growth considering the impacts it has on both full and beneficial meso-efficiency.

\subsubsection{Sefficiency for $\mathrm{M} 2 \mathrm{C}$}

The $\mathrm{iE}_{\mathrm{s}}$ and $\mathrm{cE} \mathrm{E}_{\mathrm{s}}$ values for $\mathrm{M} 2 \mathrm{C} 0$ are slightly higher than $\mathrm{M} 2 \mathrm{C} 1$, while $\mathrm{M} 2 \mathrm{C} 2$ and $\mathrm{M} 2 \mathrm{C} 3$ scenarios go down significantly (Figure 11). This suggests that useful outflow per unit of useful inflow decreases, and useful consumption per unit of effective consumption decreases relative to the reference.

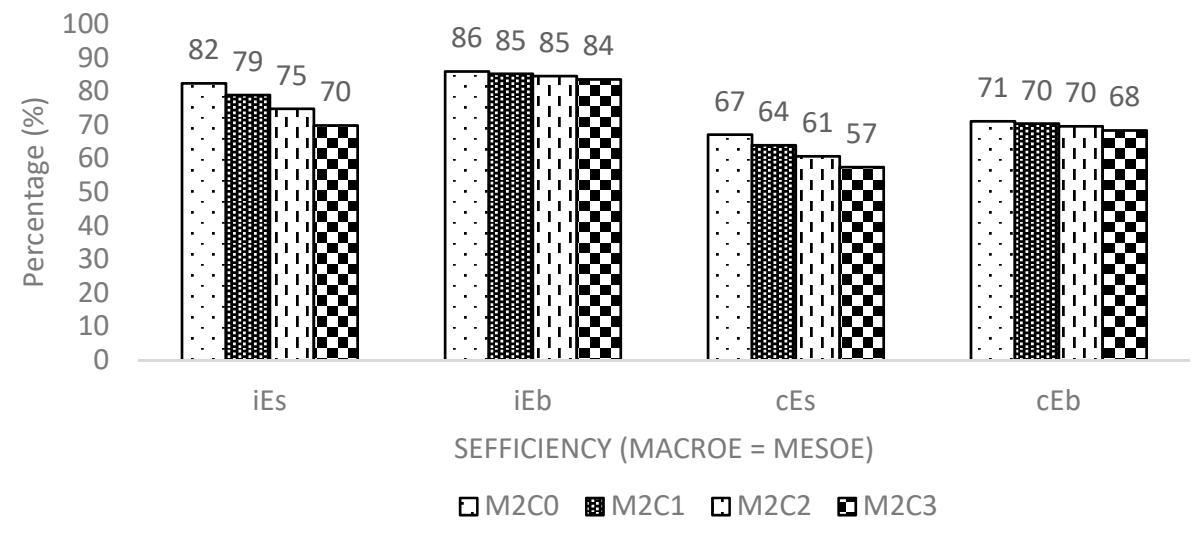

Figure 11. Sefficiency of M2C. 
The $\mathrm{cE}_{\mathrm{s}}$ values for all M2C scenarios show slightly higher values compared to one another, with $\mathrm{M} 2 \mathrm{C} 2$ and M2C3 having a difference of $4 \mathrm{pp}$ while the other two exhibit lower values (3 pp) (see Figure $9 \mathrm{~b}, \mathrm{e})$. The impacts are highest when VU or VA is decreased by $10 \%$ and VD by $18 \%$, while ET and evaporation increased by $5.3 \%$ and $9.2 \%$ respectively. Other WaP quantities are increased or decreased as presented in Table S16 of Supplementary Materials. This indicates that due to climate change (global warming is more pronounce and little increase in precipitation) volume of water in Kano River-both upstream and downstream-is reduced thereby limiting the water usage. Not only is the water physically removed from the WUS as a result of evaporation and ET, but also the resulting pollution has put it in such a degraded state with little benefits. It is worth mentioning that quantity of precipitation in a year is different from its distribution annually. Most of the time, climate change is intensifying, meaning that the increase in annual precipitation happens with fewer precipitation events. This is also true in Kano [38]. Hence, considering these scenarios and having in mind that the effect of precipitation is negligible, we can say that global warming results in decreasing the performance of Kano River.

The lowest difference happens between $\mathrm{iE}_{\mathrm{s}}$ of M2C0 and M2C1 (Figure $9 \mathrm{~b}, \mathrm{e}$ ). The useful outflow compared with useful inflow for the basin (or WUS and basin) are slightly higher than M2C1. M2C3 shows significantly lower values. This happened with an increase in precipitation by $1.4 \%$ (which is relatively little) and return flows from KRIP by $5 \%$. For the M2C case, water reduction through non-useful consumption is a dominant factor, in other words, a substantial amount of water is lost due to increased evaporation and non-beneficial evapotranspiration.

The $\mathrm{iE}_{\mathrm{b}}$ and $\mathrm{cE}_{\mathrm{b}}$ values for climate change is rather curious. It shows decreasing trends, unlike that of population growth that stay the same. An explanation for this is that quantities with higher $\mathrm{W}_{\mathrm{b}}$ are decreasing in all scenarios while those with very low beneficial weights are increasing. Alternatively, $\mathrm{iE}_{\mathrm{b}}$ and $\mathrm{cE}_{\mathrm{b}}$ values are decreasing due to the assertion that evaporation and ET have less beneficial values in Kano River (please refer to $\mathrm{W}_{\mathrm{b}}$ values in Supplementary Materials). This is an interesting result of how Sefficiency can reveal the trade-offs between quantity, water pollution, and water value at multi-level governance with climate descriptors and stakeholder enablers.

With all our assumptions, it shows that water quantities changes have an influence on the performance of Kano River model under climate change. However, the Kano River model is less sensitive to climate change impacts mainly due to the influence of global warming which is more pronounced than precipitation which can be considered to have little influence. Although global warming creates more consumption through evaporation, ET and evaporation have lower values relative to other flows. The impact which is basically percentage increase in ET and evaporation becomes a small amount, however, the driver of climate change is substantial.

\subsection{Sefficiency Results Based on Population Growth and Climate Change Impact}

\subsubsection{Sefficiency for M1B}

This sub-section now examines the impacts of both population growth and climate change on performance of KRIP concurrently. The $\mathrm{iMesoE}_{\mathrm{s}}$ and $\mathrm{cMesoE}_{\mathrm{s}}$ values for M1B1, M1B2, and M1B3 scenarios go down significantly compared to M1B0. This suggests that useful outflow per unit of useful inflow decreases, and useful consumption per unit of effective consumption decreases relative to the reference.

The $\mathrm{cMesoE}_{\mathrm{s}}$ for M1B0 shows better performance (Figure 12). The highest difference occurs between M1B0 and M1B3, making the relative consumptive impact of M1P3 on the WUS rather high (see Figure 7c,f). The impacts are highest when water applied to KRIP and ET both increase by $25 \%$, signifying that high increase in population and temperature rise resulted in decreasing the performance of KRIP. As a result of population growth much more land and water is required for planting and consequently generating more pollution. At the same time, evapotranspiration increases due to temperature rise which further compounded the problem. 


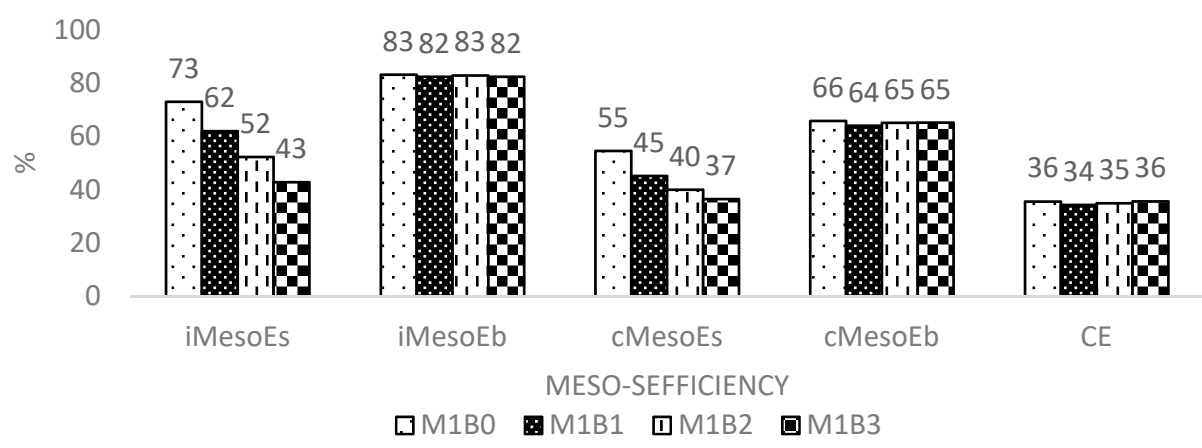

Figure 12. Sefficiency for M1B.

For iMesoE $E_{s}$, significant changes occur between inflow efficiency for all scenarios. The useful outflow compared with useful inflow for the WUS and basin of M1B is significantly lower. Another result that may have to do with the trade-offs is $\mathrm{MesoE}_{\mathrm{b}}$ values for M1B showing rather mixed results, in other words, increasing and then decreasing, i.e., the performance changes across the scenarios. This happened because WaP quantities increase even though all the quality weights decrease. However, CE remain as it is in M1C.

\subsubsection{Sefficiency for M2B}

The concurrent impact of population growth and climate change on the performance of Kano River basin was examined here. The $\mathrm{iE}_{\mathrm{s}}$ and $\mathrm{CE}_{\mathrm{s}}$ values for $\mathrm{M} 2 \mathrm{~B} 0$ are significantly higher than $\mathrm{M} 2 \mathrm{~B} 1$, while M2B2 and M2B3 values are practically equal (Figure 13). In the case of M2B1, the useful outflow per unit of useful inflow decreases, and useful consumption per unit of effective consumption decreases, while for M2B2 and M2B3 the useful outflow per unit of useful inflow and useful consumption per unit of effective consumption can be considered the same.

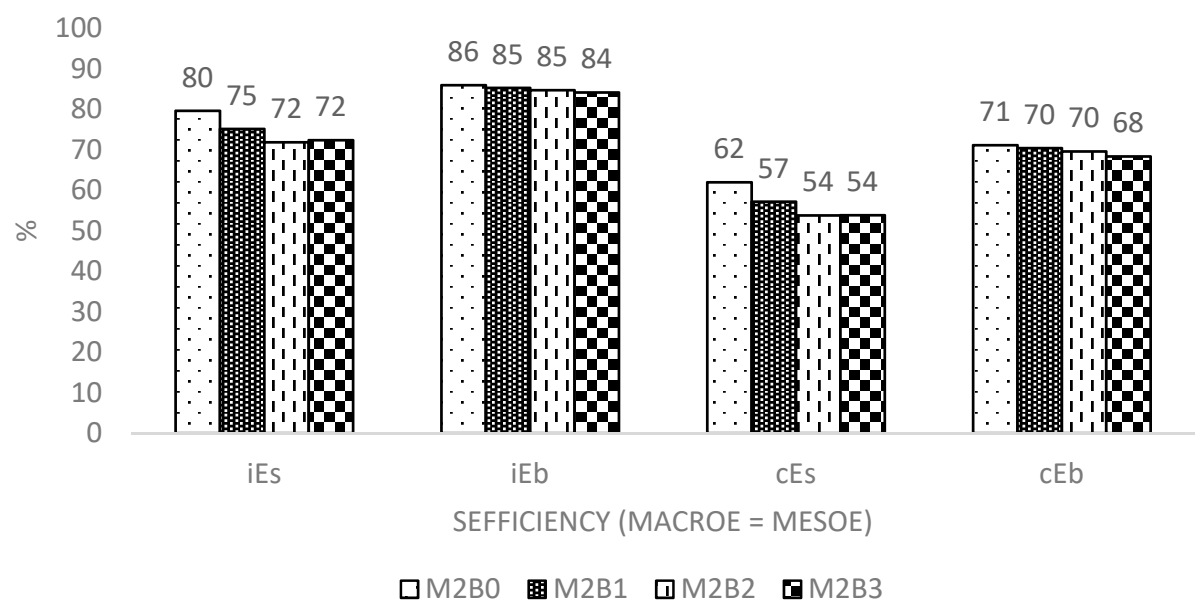

Figure 13. Sefficiency of M2B.

The $\mathrm{cE}_{\mathrm{s}}$ for $\mathrm{M} 2 \mathrm{~B} 0$ show better performance results at both levels (Figure 13). The highest difference is between M2B0 and M2B1 (Figure 9c,f), making the relative consumptive impact of M2B1 on the basin (and both WUS and the basin in case of Meso) rather high. But M2B2 and M2B3 have the same $\mathrm{iE}_{\mathrm{s}}$ and $\mathrm{cE}_{\mathrm{s}}$ values of $72 \%$ and $54 \%$, respectively, despite changes in the WaP quantities and qualities (all the quality weights decrease and some WaP quantities increase while others decrease). Although they have the same efficiency, M2B3 happened with a reduction of $70 \%$ in $\operatorname{VD}\left(125 \mathrm{Mm}^{3}\right)$, bringing the available water downstream below the minimum volume set $\left(135 \mathrm{Mm}^{3}\right)$. This indicates that under this scenario Kano River basin will be under water scarcity. It is found that water demand increases more 
within urban sector than it will in agriculture (Figure 14), because KRIP is already getting enough water. In general, potential demands for water in the basin will far exceed the available supply by 2050.

The $\mathrm{iE}_{\mathrm{b}}$ and $\mathrm{cE}_{\mathrm{b}}$ values for M2B behaves in a similar manner as M2C, showing decreasing trends. The quantities with higher $W_{b}$ are decreasing while those with very low beneficial weights increases. Alternatively, $\mathrm{iE}_{\mathrm{b}}$ and $\mathrm{cE}_{\mathrm{b}}$ values are decreasing due to the assertion that evaporation and ET have less beneficial value.

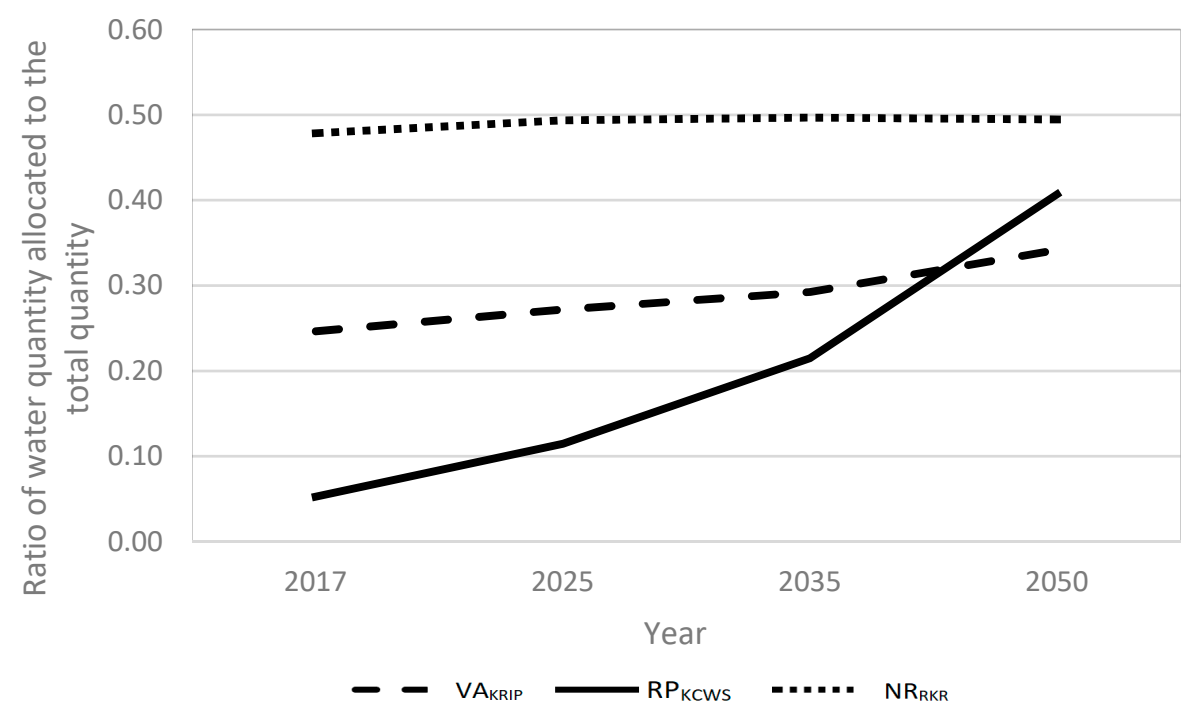

Figure 14. Ratio of water allocated to users to the total quantity.

\section{Conclusions}

Few studies considered both drivers of change to analyze and compare their sensitivity to expected changes in temperature and precipitation due to climate change and population growth. In this study, we evaluated impacts of population growth and climatic change on performance of Kano River (KR) of the Kano River basin, using an integrated approach that includes quality, quantity, and benefits called Sefficiency. We found that performance of Kano River for the current population and global warming was degraded significantly under projected population and future climate conditions. The results suggest that the performance of Kano River basin (both KR and KRIP) are sensitive to population growth and climate change under the scenarios considered. However, Kano River is less sensitive to global warming impacts, implying that population growth is the dominant driver of change. Moreover, the combined effect of population and climate change impact in Kano River basin will result in a reduction of downstream water by $70 \%$ to below the recommended volume of $135 \mathrm{Mm}^{3}$ by 2050 (i.e., to $125 \mathrm{Mm}^{3}$ ). By then the potential demands for water in the basin will far exceed the available supply resulting in serious water scarcity.

Even though beneficial weight of the flows $\left(\mathrm{W}_{\mathrm{b}}\right)$ stay the same in all M2P scenarios and quantities change, but Sefficiency does not change, if pollution (from both irrigation and the city) is ignored. This is mostly (not always) similar to other efficiency expressions that do not consider quality in their formulations. Considering these scenarios, it indicates that water quality has an important influence on the performance of Kano River under population growth. On the other hand, the quantitative efficiency values for M2C shows decreasing trends unlike that of population growth mostly due to the assertion that evaporation and ET have less beneficial value for the river itself. Alternatively, quantities with higher beneficial weights $\left(W_{b}\right)$ are decreasing while those with low beneficial weights are increasing. For KRIP, unlike full inflow (IN) and consumptive (OUT) meso-efficiencies, quantitative meso-efficiency values for climate change show increasing trends because water quality is not considered and relative quantities remain the same while beneficial consumption increases. Considering an increase in ET, one would expect an increase in the performance of KRIP, however, 
due to increase in farmland and pollution, its performance actually decreases. This underscores the fact that focusing on one or two flows (as is the general practice with classical efficiencies) can totally miss a proper water management and design policy because trade-offs in water quantity, quality, and benefits are real and cannot be ignored.

Finally, it can be concluded that population growth and global warming decrease the performance of both KRIP and Kano River basin. Increases in water demand within agricultural KRIP will primarily be due to higher irrigation demand caused by population growth. In the Kano River model (M2), increases will be due to rise in evaporation under higher temperatures. On the other hand, urban water demand will increase due to population growth. Overall, water demand will increase significantly within urban sector than it will in agriculture in Kano River basin. In general, potential demands for water in the basin will far exceed the available supply by 2050.

It is recommended that efficient management regarding the qualitative as well as quantitative aspects of water use is very critical in Kano River basin. Dealing with pollution by using wastewater treatment plants will have significant impact on the efficiency of Kano River. This study can be regarded as the first step and future studies may use the described methodology using more encompassing technologies such as sensors, remote sensing, and GIS to derive better data such as the actual irrigated land, flow rates, groundwater recharge, irrigation schedules, etc. Our results point to the need for future in-depth studies to understand the dynamics of the trade-offs that influence Sefficiencies since we are talking about understanding 30 dimensional space (one equation and about 30 variables) which is highly complex and indeed reflects the reality of water management everywhere.

Supplementary Materials: The following are available online at http:/ / www.mdpi.com/2073-4441/10/12/1766/ s1, Table S1: WaP quantities for M1P, Table S2: Percentage change in WaP quantities for M1P, Table S3: Beneficial weights for M1P, Table S4: Quality weights for M1P, Table S5: Reasons for the percentage changes in M1P, Table S6: WaP quantities for M2P, Table S7: Percentage change in WaP quantities for M2P, Table S8: Quality weights for M2P, Table S9: Beneficial weights for M2P, Table S10: Reasons for the percentage changes in M2P, Table S11: WaP quantities for M1C, Table S12: Percentage change in WaP quantities for M1C, Table S13: Beneficial weights for M1C, Table S14: Quality weights for M1C, Table S15: Reasons for the percentage changes in M1C, Table S16: WaP quantities of M2C, Table S17: Percentage change in WaP quantities for M2, Table S18: Quality weights for M2C, Table S19: Beneficial weights for M2C, Table S20: Reasons for the percentage changes in M2C, Table S21: WaP quantities for M1B, Table S22: Percentage change in WaP quantities for M1B, Table S23: Quality weights for M1B, Table S24: Beneficial weights for M1B, Table S25: WaP quantities for M2B, Table S26: Percentage change in WaP quantities for M2B, Table S27: Quality weights for M2B, Table S28: Beneficial weights for M2B.

Author Contributions: conceptualization, M.T.A.; formal analysis, M.T.A.; writing-original draft preparation, M.T.A.; writing — review and editing, N.H.; supervision, N.H.

Funding: This research was partially financed by the Portuguese Foundation for Science and Technology (FCT) under the contract UID/ECI/04047/2013 for the Centre of Territory, Environment and Construction (CTAC).

Acknowledgments: The support provided by the farmers, management of Hadejia-Jama'are River Basin Development Authority (H-JRBDA) and Kano State Water Board are duly acknowledged. Moreover, the authors thank the anonymous reviewers for their helpful comments.

Conflicts of Interest: The authors declare no conflict of interest.

\section{References}

1. Okello, C.; Tomasello, B.; Greggio, N.; Wambiji, N.; Antonellini, M. Impact of population growth and climate change on the freshwater resources of Lamu Island, Kenya. Water 2015, 7, 1264-1290. [CrossRef]

2. Kifle, A.B.; Mengistu, T.G.; Stoffberg, G.H.; Tadesse, T. Climate change and population growth impacts on surface water supply and demand of Addis Ababa, Ethiopia. Clim. Risk Manag. 2017, 18, 21-33. [CrossRef]

3. United Nations Department of Economic and Social Affairs. World Population Prospects The 2017 Revision Key Findings and Advance Tables. In World Popul Prospect 2017; United Nations Department of Economic and Social Affairs: New York, NY, USA, 2017; pp. 1-46. [CrossRef]

4. Odjugo, P. General overview of climate change impacts in Nigeria. J. Hum. Ecol. 2010, 29, 47-55. [CrossRef]

5. Tambo, J.A.; Abdoulaye, T. Smallholder farmers' perceptions of and adaptations to climate change in the Nigerian savanna. Reg. Environ. Chang. 2013, 13, 375-388. [CrossRef] 
6. Loucks, D.P. Managing Water as a Critical Component of a Changing World. Water Resour. Manag. 2017, 1, 2905-2916. [CrossRef]

7. Masih, I.; Ahmad, M.; Uhlenbrook, S.; Turral, H.; Karimi, P. Analysing streamflow variability and water allocation for sustainable management of water resources in the semi-arid Karkheh river basin, Iran. Phys. Chem. Earth 2009, 34, 329-340. [CrossRef]

8. Mohammed, R.; Scholz, M. Adaptation Strategy to Mitigate the Impact of Climate Change on Water Resources in Arid and Semi-Arid Regions: A Case Study. Water Resour. Manag. 2017, 31, 3557-3573. [CrossRef]

9. Goes, B.J.M. Effects of river regulation on aquatic macrophyte growth and floods in the Hadejia-Nguru wetlands and flow in the Yobe River, northern Nigeria; implications for future water management. River Res. Appl. 2002, 18, 81-95. [CrossRef]

10. Ahmad, M.T.; Haie, N.; Yen, H.; Tuqan, N.A.S. Sefficiency of a Water Use System: The Case of Kano River Irrigation Project, Nigeria. Int. J. Civ. Eng. 2018, 16, 929-939. [CrossRef]

11. Abou Kheira, A.A. Comparative assessment of new design criteria for irrigation improvement in Egypt. Water Resour. Manag. 2009, 23, 2317-2342. [CrossRef]

12. Ghahroodi, E.M.; Noory, H.; Liaghat, A.M. Performance evaluation study and hydrologic and productive analysis of irrigation systems at the Qazvin irrigation network (Iran). Agric. Water Manag. 2015, 148, 189-195. [CrossRef]

13. Angella, G.; García Vila, M.; López, J.M.; Barraza, G.; Salgado, R.; Prieto Angueira, S.; Tomsic, P.; Fereres, E. Quantifying yield and water productivity gaps in an irrigation district under rotational delivery schedule. Irrig. Sci. 2016, 34, 71-83. [CrossRef]

14. Merchán, D.; Causapé, J.; Abrahão, R.; García-Garizábal, I. Assessment of a newly implemented irrigated area (Lerma Basin, Spain) over a 10-year period. I: Water balances and irrigation performance. Agric. Water Manag. 2015, 158, 277-287. [CrossRef]

15. García-Bolaños, M.; Borgia, C.; Poblador, N.; Dia, M.; Seyid, O.M.V.; Mateos, L. Performance assessment of small irrigation schemes along the Mauritanian banks of the Senegal River. Agric. Water Manag. 2011, 98, 1141-1152. [CrossRef]

16. García-Garizábal, I.; Causapé, J.; Abrahao, R. Application of the irrigation land environmental evaluation tool for flood irrigation management and evaluation of water use. Catena 2011, 87, 260-267. [CrossRef]

17. Barros, R.; Isidoro, D.; Aragüés, R. Long-term water balances in La Violada Irrigation District (Spain): II. Analysis of irrigation performance. Agric. Water Manag. 2011, 98, 1569-1576. [CrossRef]

18. Van Halsema, G.; Lencha, B.K.; Assefa, M.; Hengsdijk, H.; Wesseler, J. Performance assessment of smallholder irrigation in the central rift valley of Ethiopia. Irrig. Drain. 2011, 60, 622-634. [CrossRef]

19. Mateos, L.; Lozano, D.; Baghil, A.B.O.; Diallo, O.A.; Gómez-Macpherson, H.; Comas, J.; Connor, D. Irrigation performance before and after rehabilitation of a representative, small irrigation scheme besides the Senegal River, Mauritania. Agric. Water Manag. 2010, 97, 901-909. [CrossRef]

20. Kifle, M.; Gebremicael, T.G.; Girmay, A.; Gebremedihin, T. Effect of surge flow and alternate irrigation on the irrigation efficiency and water productivity of onion in the semi-arid areas of North Ethiopia. Agric. Water Manag. 2017, 187, 69-76. [CrossRef]

21. Borgia, C.; García-Bolaños, M.; Li, T.; Gómez-Macpherson, H.; Comas, J.; Connor, D.; Mateos, L. Benchmarking for performance assessment of small and large irrigation schemes along the Senegal Valley in Mauritania. Agric. Water Manag. 2013, 121, 19-26. [CrossRef]

22. Longxia, Q.; Wang, H.; Zhang, K. Evaluation Criteria and Model for Risk Between Water Supply and Water Demand and its Application in Beijing. Water Resour. Manag. 2014, 28, 4433-4447. [CrossRef]

23. Haro, D.; Solera, A.; Paredes, J.; Andreu, J. Methodology for Drought Risk Assessment in Within-year Regulated Reservoir Systems. Application to the Orbigo River System (Spain). Water Resour. Manag. 2014, 28, 3801-3814. [CrossRef]

24. Preziosi, E.; Del Bon, A.; Romano, E.; Petrangeli, A.B.; Casadei, S. Vulnerability to Drought of a Complex Water Supply System. The Upper Tiber Basin Case Study (Central Italy). Water Resour. Manag. 2013, 27, 4655-4678. [CrossRef]

25. Akhbari, M.; Grigg, N.S. A Framework for an Agent-Based Model to Manage Water Resources Conflicts. Water Resour. Manag. 2013, 27, 4039-4405. [CrossRef]

26. Haie, N.; Keller, A.A. Macro, Meso, and Micro-Efficiencies in Water Resources Management: A New Framework Using Water Balance. JAWRA J. Am. Water Resour. Assoc. 2012, 48, 235-243. [CrossRef] 
27. De Fraiture, C.; Wichelns, D. Satisfying future water demands for agriculture. Agric. Water Manag. 2010, 97, 502-511. [CrossRef]

28. UN-Water. WWDR4: Managing Water under Uncertainty and Risk; UN-Water: Geneva, Switzerland, 2012; Volume 1.

29. UNEP. Towards a Green Economy: Pathways to Sustainable Development and Poverty Eradication-A Synthesis for Policy Makers; UNEP: Nairobi, Kenya, 2011; pp. 1-34.

30. Burt, C.M.; Clemmens, A.J.; Strelkoff, T.S.; Hardy, L.; Howell, T.A.; Eisenhauer, D.E. Irrigation performance measures: Efficiency and uniformity. J. Irrig. Drain Eng. 1997, 123, 423-442. [CrossRef]

31. Labadie, J.W. Optimal Operation of Multireservoir Systems: State-of-the-Art Review. J. Water Resour. Plan Manag. 2004, 130, 93-111. [CrossRef]

32. Wang, Y.J.; Qin, D.H. Influence of climate change and human activity on water resources in arid region of Northwest China: An overview. Adv. Clim. Chang. Res. 2017, 8, 268-278. [CrossRef]

33. Simonovic, S.P. Bringing Future Climatic Change into Water Resources Management Practice Today. Water Resour. Manag. 2017, 31, 2933-2950. [CrossRef]

34. Pierleoni, A.; Camici, S.; Brocca, L.; Moramarco, T.; Casadei, S. Climate change and decision support systems for water resource management. Procedia Eng. 2014, 70, 1324-1333. [CrossRef]

35. Narsimlu, B.; Gosain, A.K.; Chahar, B.R. Assessment of Future Climate Change Impacts on Water Resources of Upper Sind River Basin, India Using SWAT Model. Water Resour. Manag. 2013, 27, 3647-3662. [CrossRef]

36. Veijalainen, N.; Dubrovin, T.; Marttunen, M.; Vehviläinen, B. Climate Change Impacts on Water Resources and Lake Regulation in the Vuoksi Watershed in Finland. Water Resour. Manag. 2010, 24, 3437-3459. [CrossRef]

37. Bichi, M.H.; Anyata, B.U. Industrial waste pollution in the Kano river basin. Environ. Manag. Heal. 1999, 10, 112-116. [CrossRef]

38. Mohammed, M.; Abdulhamid, A.; Badamasi, M.; Ahmed, M. Rainfall Dynamics and Climate Change in Kano, Nigeria. J. Sci. Res. Rep. 2015, 7, 386-395. [CrossRef]

39. Haie, N.; Keller, A.A. Macro, meso, and micro-efficiencies and terminologies in water resources management: A look at urban and agricultural differences. Water Int. 2014, 39, 35-48. [CrossRef]

40. Sato, T.; Qadir, M.; Yamamoto, S.; Endo, T.; Zahoor, A. Global, regional, and country level need for data on wastewater generation, treatment, and use. Agric. Water Manag. 2013, 130, 1-13. [CrossRef]

41. Swennenhuis, J. CROPWAT 8.0. 2010. Available online: http://www.fao.org/land-water/databases-andsoftware/cropwat/en/ (accessed on 10 January 2016).

42. IUCN-HNWCP. Water Management Options for the Hadejia-Jama'are-Yobe River Basin, Northern Nigeria; IUCN Wetlands Programme Newsletter: Abuja, Nigeria, 1999; pp. 8-11.

43. Goes, B.J.; Zabudum, A.N. Hydrology of the Hadejia-Jama'are-Yobe River Basin 1996/7 and 1997/8; IUCN-The World Conservation Union: Abuja, Nigeria, 1998.

44. Oyebande, L. Effects of reservoir operation on the hydrological regime and water availability in northern Nigeria. In Man's Influence on Freshwater Ecosystems and Water Use; IAHS Publishing: Edinburgh, UK, 1995; p. 230.

45. Heydari, M.M.; Heydari, M. Evaluation of pan coefficient equations for estimating reference crop evapotranspiration in the arid region. Arch. Agron. Soil Sci. 2014, 60, 715-731. [CrossRef]

46. Mara, D. Domestic Wastewater Treatment in Developing Countries; Earthscan: London, UK, $2004 ;$ p. 74. [CrossRef]

47. Oyebande, L. Streamflow Regime Change and Ecological Response in the Lake Chad Basin in Nigeria; IAHS Publishing: Edinburgh, UK, 2001; pp. 101-112.

48. National Population Commission. 2006 Population and Housing Census of the Federal Republic of Nigeria Priority Tables (LGA) (Volume II): Housing Characteristics and Amenities Table; National Population Commission: Abuja, Nigeria, 2010. Available online: http:/ / population.gov.ng/core-activities/surveys/dataset/2006phc-priority-tables/ (accessed on 22 November 2017).

49. United Nations Department of Economic and Social Affairs. The World's Cities in 2016: Data Booklet; United Nations Department of Economic and Social Affairs: Quito, Ecuador, 2016; p. 29. [CrossRef]

50. Parkman. Greater Kano Water Feasibility Study; Final Report Volume 1-Main Report; Parkman: Kano, Nigeria, 2000. 
51. Grijsen, J.G.; Brown, C.; Tarhule, A.; Ghile, A.B.; Taner, Ü.; Talbi-Jordan, A.; Doffou, H.N.; Guero, A.; Dessouassi, R.Y.; Kone, S.; et al. Climate Risk Assessment for Water Resources Development in the Niger River Basin Part I: Context and Climate Projections. Clim. Var. 2013, 37-56. [CrossRef]

52. Steduto, P.; Hsiao, T.C.; Fereres, E. On the conservative behavior of biomass water productivity. Irrig. Sci. 2007, 25, 189-207. [CrossRef] 